\title{
The chemopreventive properties of chlorogenic acid reveal a potential new role for the microsomal glucose-6-phosphate translocase in brain tumor progression
}

\author{
Anissa Belkaid, Jean-Christophe Currie, Julie Desgagnés and \\ Borhane Annabi*
}

Address: Laboratoire d'Oncologie Moléculaire, Département de Chimie, Centre BIOMED, Université du Québec à Montréal, Montreal, Quebec, Canada

Email: Anissa Belkaid - belkaid.anissa@courrier.uqam.ca; Jean-Christophe Currie - currie.jean-christophe@courrier.uqam.ca; Julie Desgagnés - julie.desgagnes@umontreal.ca; Borhane Annabi* - annabi.borhane@uqam.ca

* Corresponding author

Published: 27 March 2006

Cancer Cell International2006, 6:7 doi:10.1 186/1475-2867-6-7

This article is available from: http://www.cancerci.com/content/6/I/7

(C) 2006Belkaid et al; licensee BioMed Central Ltd.

This is an Open Access article distributed under the terms of the Creative Commons Attribution License (http://creativecommons.org/licenses/by/2.0), which permits unrestricted use, distribution, and reproduction in any medium, provided the original work is properly cited.

\begin{abstract}
Background: Chlorogenic acid (CHL), the most potent functional inhibitor of the microsomal glucose-6phosphate translocase (G6PT), is thought to possess cancer chemopreventive properties. It is not known, however, whether any G6PT functions are involved in tumorigenesis. We investigated the effects of CHL and the potential role of G6PT in regulating the invasive phenotype of brain tumor-derived glioma cells.

Results: RT-PCR was used to show that, among the adult and pediatric brain tumor-derived cells tested, U-87 glioma cells expressed the highest levels of G6PT mRNA. U-87 cells lacked the microsomal catalytic subunit glucose-6-phosphatase (G6Pase)- $\alpha$ but expressed G6Pase- $\beta$ which, when coupled to G6PT, allows G6P hydrolysis into glucose to occur in non-glyconeogenic tissues such as brain. $\mathrm{CHL}$ inhibited U-87 cell migration and matrix metalloproteinase (MMP)-2 secretion, two prerequisites for tumor cell invasion. Moreover, $\mathrm{CHL}$ also inhibited cell migration induced by sphingosine-I-phosphate (SIP), a potent mitogen for glioblastoma multiform cells, as well as the rapid, SIP-induced extracellular signal-regulated protein kinase phosphorylation potentially mediated through intracellular calcium mobilization, suggesting that G6PT may also perform crucial functions in regulating intracellular signalling. Overexpression of the recombinant G6PT protein induced U-87 glioma cell migration that was, in turn, antagonized by CHL. MMP-2 secretion was also inhibited by the adenosine triphosphate (ATP)depleting agents 2-deoxyglucose and 5-thioglucose, a mechanism that may inhibit ATP-mediated calcium sequestration by G6PT.
\end{abstract}

Conclusion: We illustrate a new G6PT function in glioma cells that could regulate the intracellular signalling and invasive phenotype of brain tumor cells, and that can be targeted by the anticancer properties of $\mathrm{CHL}$.

\section{Background}

The beneficial effects of dietary polyphenols on human health have been widely assumed to act through various biological effects such as free radical scavenging, metal chelation, modulation of enzymatic activity and altering signal transduction pathways [1-3]. Epidemiological studies have also highlighted the association between the consumption of polyphenol-rich food and beverages and the prevention of various human diseases $[4,5]$. Among these polyphenols, the antitumor activities of flavonoids as well 
as the inhibition of carcinogenesis by polyphenols has revealed properties beneficial for the use of nutraceuticals in cancer therapy [6-8]. Among the sources of these anticancer polyphenols, modern phytochemical research shows that tea contains a large number of plant secondary metabolites exhibiting different chemical structures such as amino acids, catechins, purine alkaloids, and chlorogenic acid (CHL), and where each group of compounds possesses some unique biological properties [9]. While green tea catechins have now been established as having chemopreventive effects $[10,11]$, the impact of $\mathrm{CHL}$, to which have been attributed possible cancer chemoprevention properties, is not well understood $[12,13]$. Interestingly, CHL inhibition of matrix metalloproteinase (MMP)-9 secretion, an MMP known to be involved in tumor cell invasion and metastasis, was recently reported but the anti-cancer intracellular molecular mechanisms through which CHL effects occur are remained unexplored [14]. This property, however, adds up to CHL's antioxydant and anti-inflammatory properties $[15,16]$.

CHL derivatives have been shown to selectively inhibit endoplasmic reticulum (ER) glucose-6-phosphate (G6P) transport, and hence microsomal glucose-6-phosphatase (G6Pase) activity both in isolated microsomes [17] and in vivo $[18,19]$. CHL is a specific, reversible, competitive inhibitor of G6PT [20], and it has no effect on the intraluminal, G6P-hydrolytic subunit [21]. In intact cells, the CHL derivative and G6PT inhibitor S3483 was found to inhibit G6P transport in microsomes isolated from polymorphonuclear neutrophils (PMN) and from differentiated promyelocytic HL-60 cells [22]. Interestingly, the PMN phenotype in glycogen storage disease (GSD) type $1 \mathrm{~b}$, a clinical condition where the G6PT gene or protein is defective $[22,23]$, includes diminution in several processes such as respiratory burst, chemotaxis, phagocytosis and calcium signalling [24-26]. Alterations in several biochemical parameters - glucose phosphorylation, calcium mobilization, and hexose uptake and transport - have been described as possible mechanisms through which the G6PT functional defects may be involved [27-29]. Since cells such as PMN have no detectable G6Pase activity, G6PT must play a role different from that exerted in the liver, for instance, where it is functionally coupled to the G6Pase enzyme. Moreover, G6PT functions have never been investigated in brain tumor-derived cells. It has been hypothesized that G6PT might function as a G6P receptor/sensor [23] or that it could favor calcium sequestration in the ER lumen [30]. Such roles have not yet been evidenced, neither the alternate potential G6PT-regulated cellular functions explored.

In the present work two topics have been addressed. Does functional inhibition of G6PT regulate any brain tumorderived cells' tumorigenic properties, such as MMP-medi-

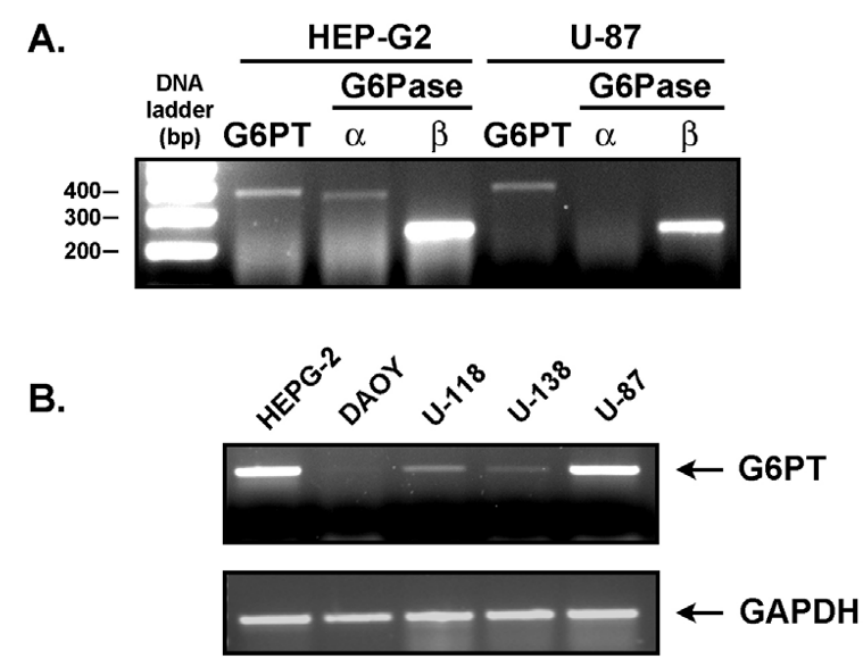

Figure I

U-87 glioma cells express G6PT and G6Pase- $\beta$ transcripts with the highest G6PT transcript levels among brain tumor-derived cell lines. Several brain tumor-derived cell lines (glioma : U-87, U-I I 8, U- I 38; medulloblastoma : DAOY) were cultured until cells reached approximately $90 \%$ confluence. Total RNA was extracted and RT-PCR performed in order to generate the CDNA that reflects the gene expression levels of G6PT (380 bp), G6Pase- $\alpha$ (360 bp), and G6Pase- $\beta$ (236 bp) as described in the methods section. HEP-G2 hepatoma cells were used as positive controls for the presence of all three genes. GAPDH gene expression was used as an internal control for each cell line tested.

ated extracellular matrix (ECM) hydrolytic activity or cell migration ? If so, can a connection be made between G6PT functions and a role in intracellular signalling that regulates the invasive phenotype ? Inhibition of the microsomal G6PT functions was modeled by the addition of CHL, which is a highly specific inhibitor of G6PT [31], while upregulation of G6PT was performed through cDNA transient transfection. The results demonstrate that G6PT may regulate the brain tumor-derived invasive phenotype by controlling intracellular signalling that leads to cell migration. Moreover, we provide the first molecular rationale for the anticancer properties of CHL in the regulation of MMP secretion.

\section{Results}

U-87 glioma cells express the highest levels of G6PT transcript among brain tumor-derived cell lines

Gene expression levels of the microsomal glucose-6-phosphate transporter (G6PT), as well as of the two glucose-6phosphatase $\alpha$ and $\beta$ isoforms, were first assessed. Total RNA was extracted from HEP-G2 hepatoma and U-87 glioma cells, and then RT-PCR was performed as described in the Methods section. As expected for a cell line derived from a neoglucogenic tissue, we show that HEP-G2 cells 
A.
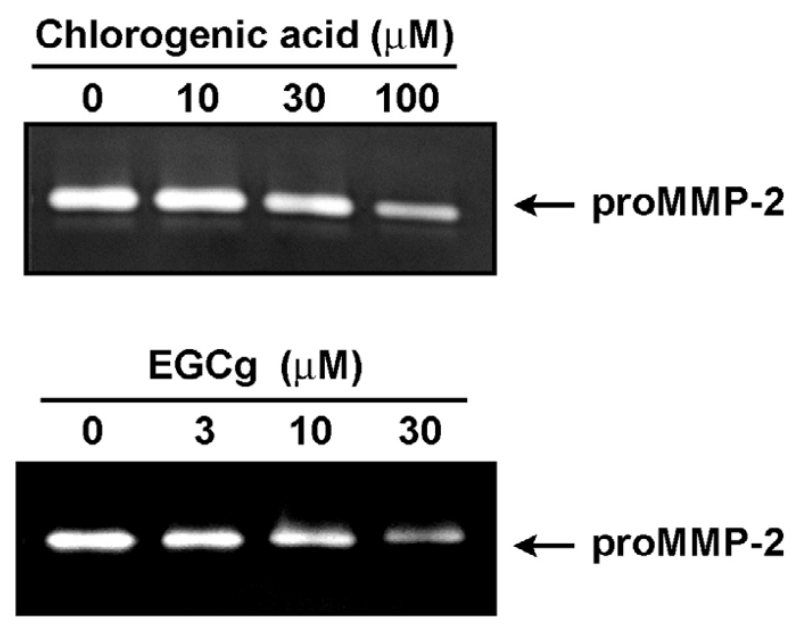

B.

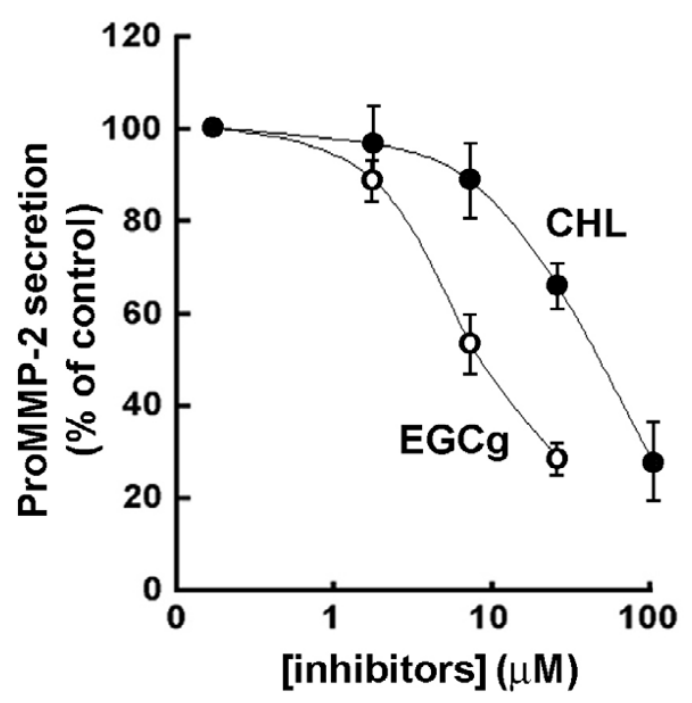

C.

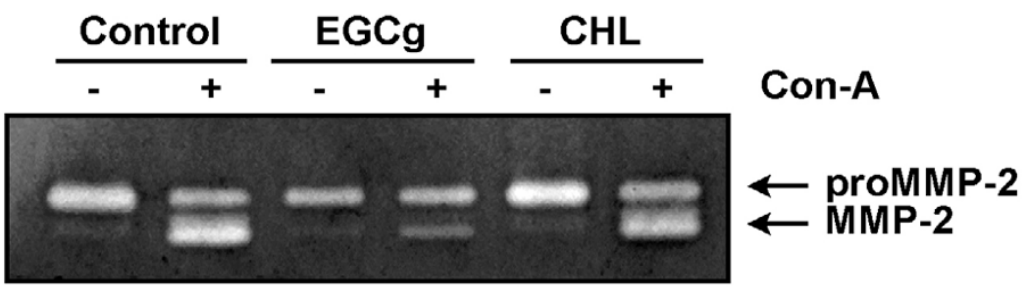

\section{Figure 2}

The G6PT inhibitor chlorogenic acid reduces proMMP-2 secretion in U-87 glioma cells. (A) U-87 glioma cells were serum-starved in the presence of increasing concentrations of $\mathrm{CHL}$ and of the green tea catechin EGCg for $18 \mathrm{hrs}$. Conditioned media was collected and proMMP-2 gelatinolytic activity assessed by zymography as described in the methods section. (B) The extent of proMMP-2 hydrolytic activity was quantified by scan densitometry and is the average \pm SEM of three independent experiments. (C) The effect of CHL and EGCg on MTI-MMP functions was also monitored. U-87 cells were cultured in the presence of an exogenous source of proMMP-2 in the presence of $10 \mu \mathrm{g} / \mathrm{ml}$ concanavalin-A, a MTI-MMP-mediated inducer of proMMP-2 activation, and of EGCg or CHL. The extent of proMMP-2 activation was assessed by gelatin zymography. 

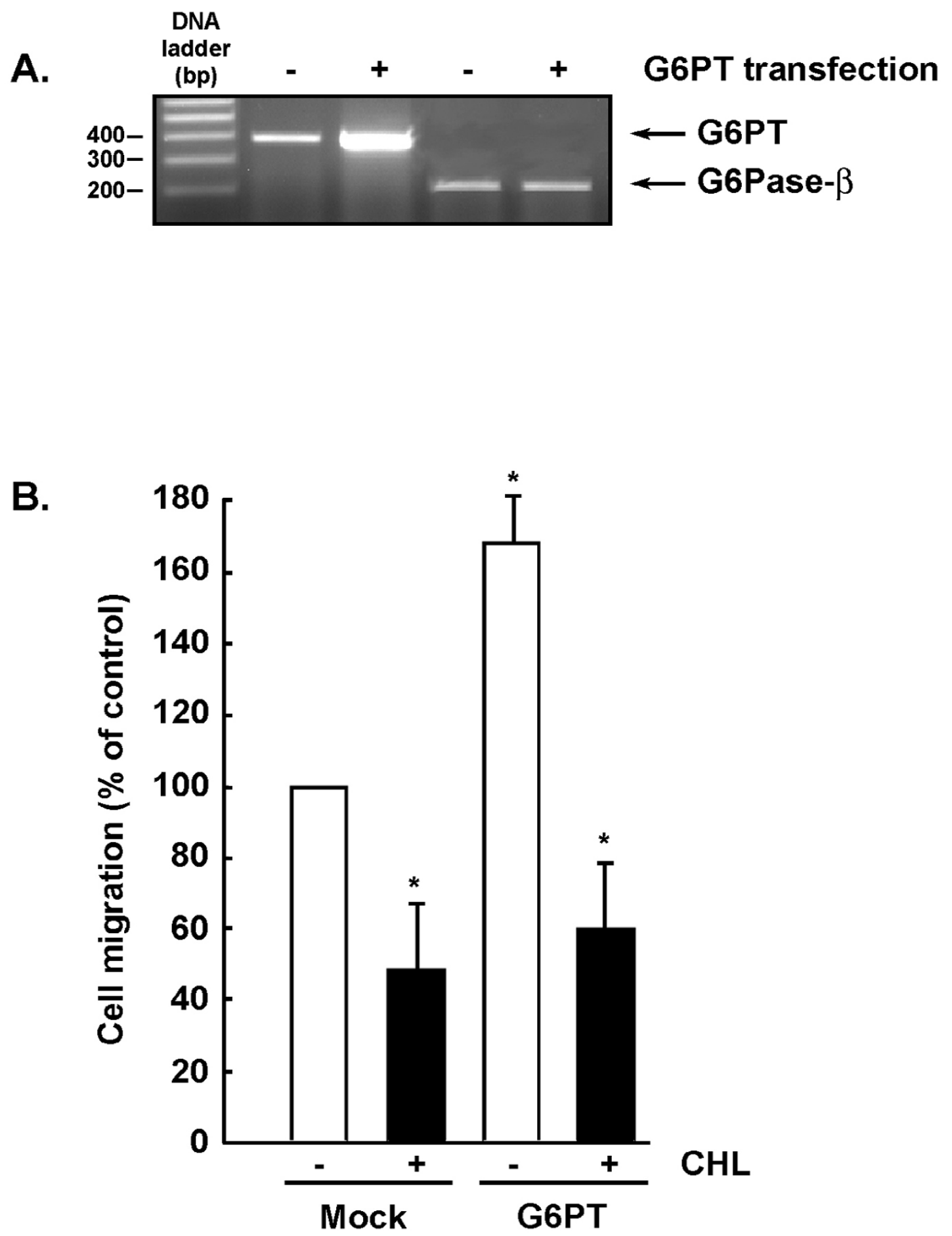

Figure 3

G6PT regulates U-87 glioma cells migration. U-87 glioma cells were transfected with a cDNA plasmid encoding G6PT [36] as described in the methods section. (A) Total RNA was extracted from Mock or G6PT-transfected cells (Tx) and RTPCR was independently performed for G6PT and G6Pase- $\beta$ gene expression. (B) Basal cell migration was assessed in Mock and G6PT-transfected U-87 cells as described in the Methods section in the presence or absence of $100 \mu M \mathrm{CHL}$. Six independent experiments were performed and the average of more than 10 microscopic fields for each experimental condition shown with SEM. 
A.

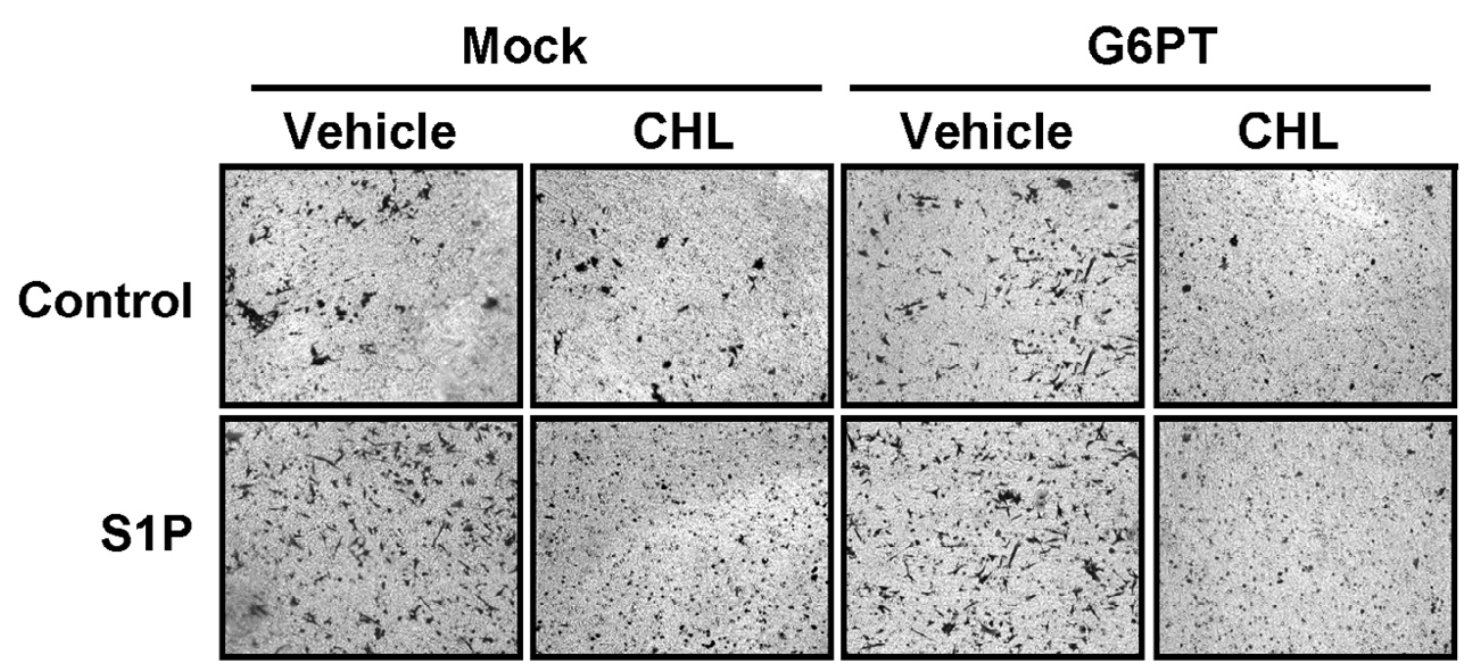

B.

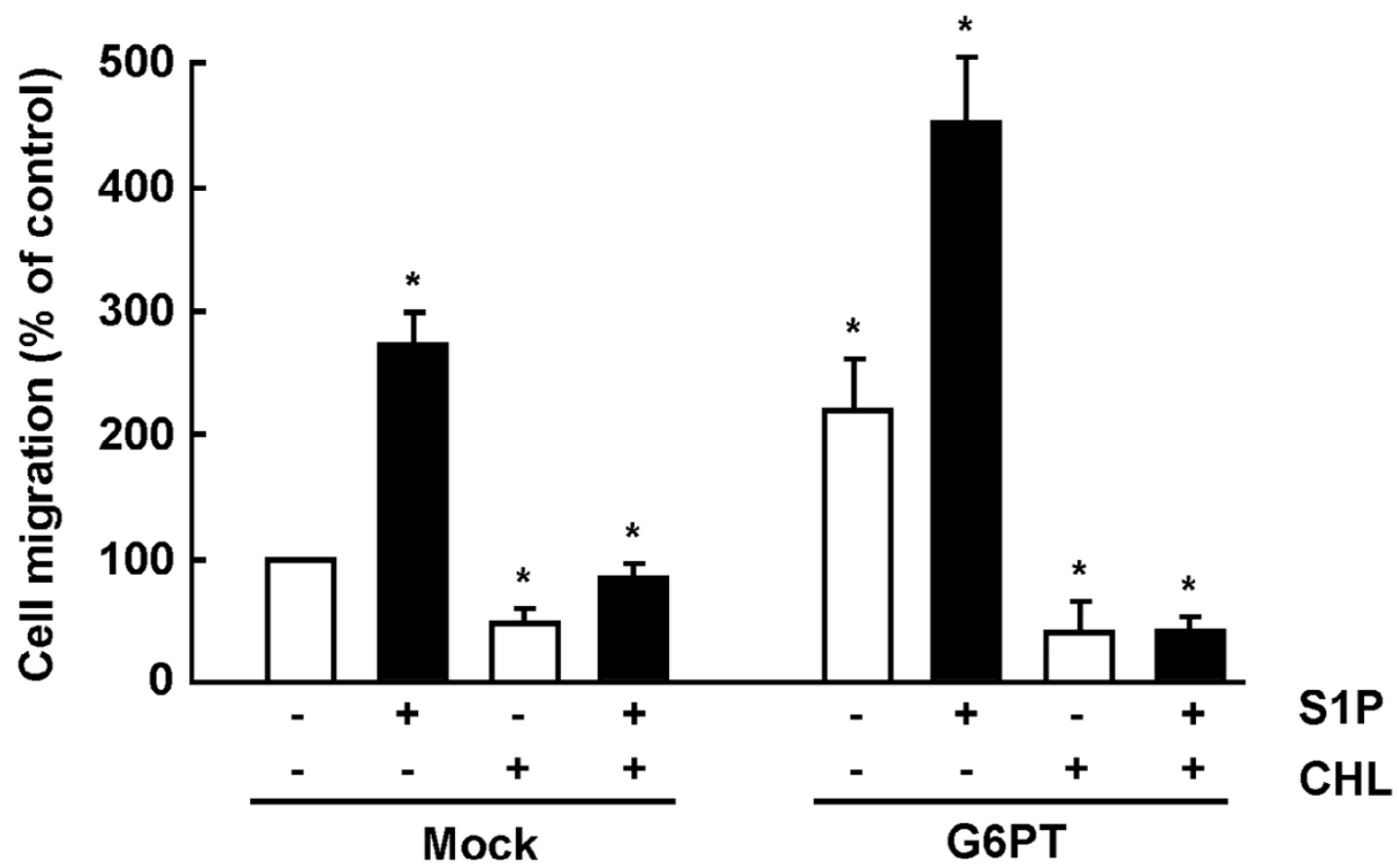

Figure 4

Chlorogenic acid inhibits sphingosine-I-phosphate-induced U-87 glioma cells migration. (A) Control (Mock) or G6PT-transfected U-87 glioma cells were seeded on gelatin-coated filters and cell migration was assessed in the presence or absence of $100 \mu \mathrm{M} \mathrm{CHL}, I \mu \mathrm{M}$ SIP, or a combination of both. (B) Quantification was performed as described in the Methods section and is representative of 6 independent experiments. The average of more than 10 microscopic fields for each experimental condition is shown with SEM.

express all three components of the G6Pase system with G6Pase- $\beta$ being predominant amongst these three (Fig. 1a). RT-PCR was also performed on RNA extracted from
U-87 glioma cells. In contrast to HEP-G2, only G6PT and G6Pase- $\beta$ transcripts were significantly expressed, with very low to undetectable G6Pase- $\alpha$ present (Fig. 1a). This 


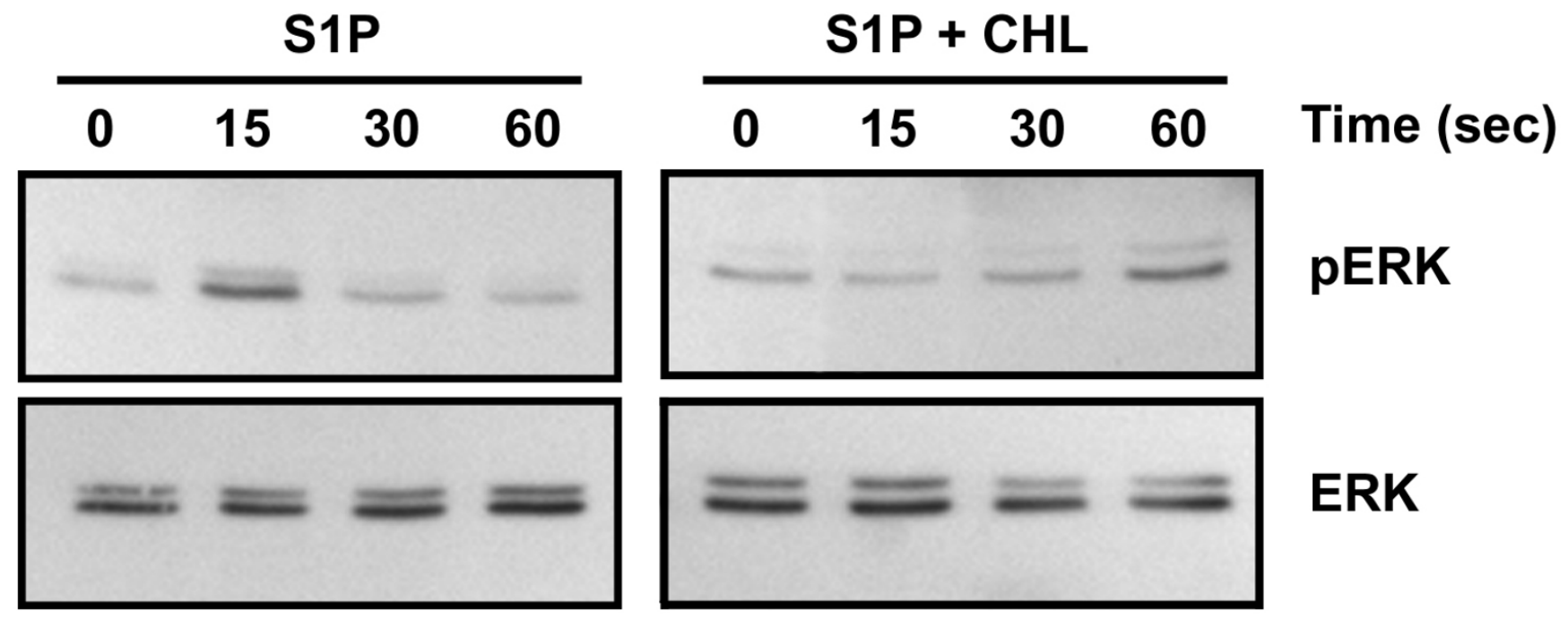

Figure 5

Chlorogenic acid inhibits sphingosine-I-phosphate-induced ERK phosphorylation in U-87 glioma cells. Serumstarved U-87 glioma cells were pretreated with for 30 minutes with $100 \mu$ M CHL. One $\mu$ M SIP was then added to the media and incubation performed for 15, 30, and 60 seconds. Cells were then rapidly harvested and lysates prepared as described in the Methods section. The extent of ERK phosphorylation was monitored by immunoblotting using antibodies against $\mathrm{P}$-ERK and total ERK.

is in agreement with previous reports demonstrating the lack of G6Pase- $\alpha$ expression in brain-derived cells [32]. We also monitored the levels of G6PT in a brain tumor cell line derived from a pediatric medulloblastoma (DAOY), as well as in the U-118 and U-138 glioma cell lines. Interestingly, among the adult brain tumor-derived cell lines, U-87 glioma cells expressed the highest level of G6PT (Fig. 1b), while DAOY cells expressed very low to undetectable G6PT transcripts. This suggests that G6PT expression in brain tumor cells may be regulated during development.

\section{The G6PT inhibitor chlorogenic acid reduces proMMP-2 secretion in $\mathbf{U}-87$ glioma cells}

We next assessed the potential functions that G6PT may affect in the invasive phenotype of U-87 glioma cells. Based on the assumption that CHL is able to efficiently penetrate inside the cells [33], U-87 glioma cells were treated with different concentrations of $\mathrm{CHL}$ and the secretion of matrix metalloproteinase (MMP)-2 was monitored by zymography. CHL significantly inhibited latent proMMP-2 secretion (Fig. 2a) and another tea-derived compound, epigallocatechin gallate (EGCg), was just as efficient (Fig. 2a and 2b). CHL was found not to induce any early/late apoptotic or necrotic processes in U-87 glioma cells as assessed by Annexin-V/Propidium iodine double staining and flow cytometry (not shown). Since EGCg has also been reported to inhibit membrane type (MT)1-MMP from activating the latent proMMP-2 in glioblastoma cells [34], we further assessed the possible effects of CHL on MT1-MMP-mediated proMMP-2 activation. Cells were incubated with an exogenous source of proMMP-2 and were treated (or not) with concanavalin-A in order to trigger proMMP-2 activation [35]. While EGCg clearly inhibited MT1-MMP-mediated activation of proMMP-2, CHL had no such inhibitory effect (Fig. 2c).

\section{Chlorogenic acid inhibits G6PT-mediated U-87 glioma cell migration}

The role of G6PT in U-87 glioma cell migration was next assessed. Cells were transfected, or not (Mock), with G6PT cDNA [36] and basal cell migration assay was performed on gelatin-coated filters using modified Boyden chambers as described in the Methods section. Transfection of G6PT cDNA specifically increased G6PT transcript levels, while levels of G6Pase- $\beta$ remained unaffected (Fig. 3a). Interestingly, the sole effect of G6PT overexpression was to increase the basal migration of U-87 glioma cells (Fig. 3b, white bars), while CHL inhibited both basal and G6PTinduced cell migration (Fig. 3b, black bars). This suggests that G6PT functions may, in part, regulate the invasive phenotype of U-87 glioma cells.

\section{Chlorogenic acid inhibits sphingosine- I-phosphate- induced U-87 glioma cells migration}

Sphingosine-1-phosphate (S1P) is a bioactive lipid which is present at high levels in brain tissue [36] and which acts as a potent mitogen for glioblastoma multiform cells [38]. 
A.
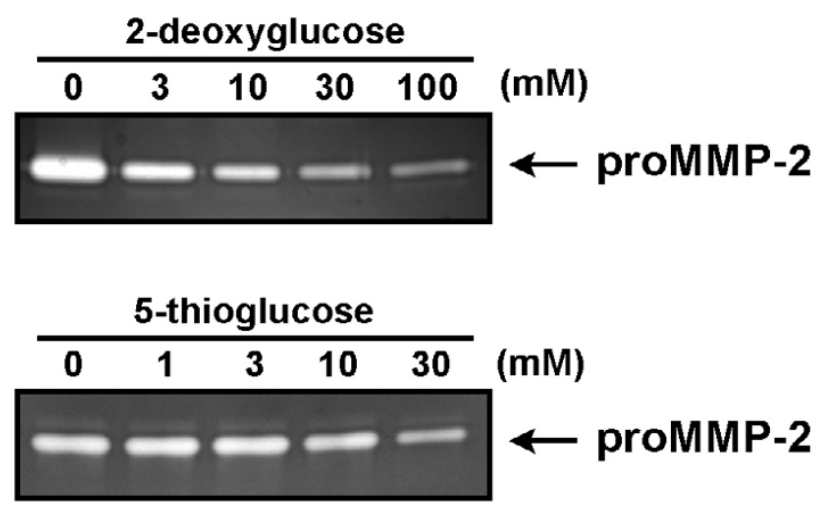

B.

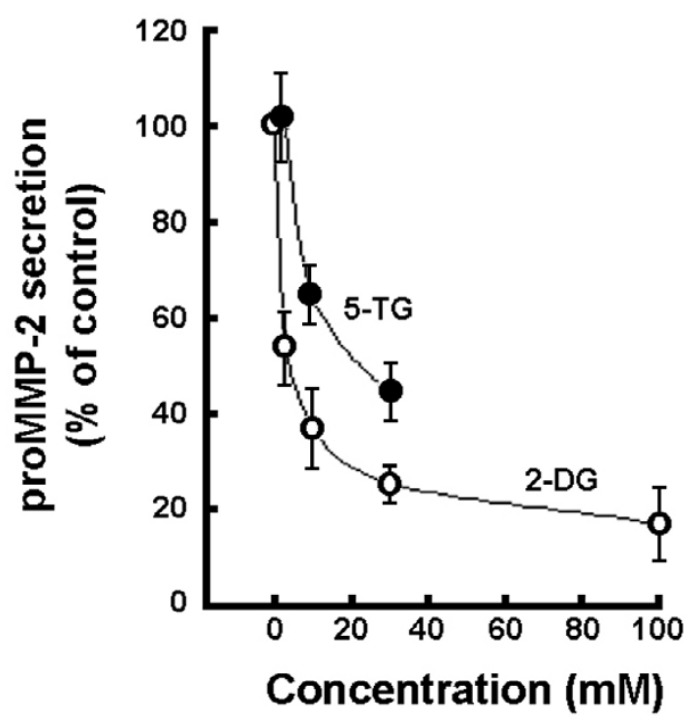

C.

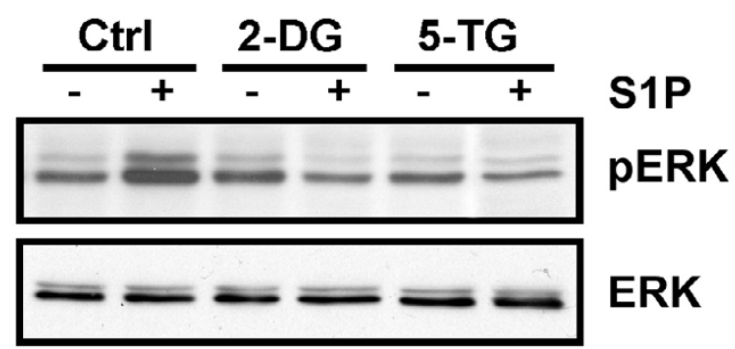

Figure 6

Intracellular ATP-depleting agents inhibit proMMP-2 secretion and antagonize SIP-induced ERK phosphorylation in U-87 glioma cells. (A) Serum-starved U-87 glioma cells were treated for $18 \mathrm{hrs}$ with individual concentrations of 2 deoxyglucose or 5-thioglucose, two well established ATP-depleting agents [6I]. Conditioned media were collected and the hydrolytic activity of proMMP-2 was assessed using gelatin-zymography as described in the Methods section. (B) The extent of proMMP-2 hydrolytic activity was quantified by scan densitometry in 5-TG- (black circles) and 2-DG- (white circles) treated cells, and is the average \pm SEM of three independent experiments. (C) Serum-starved U-87 glioma cells were pretreated for 30 minutes with $100 \mathrm{mM}$ 2-deoxyglucose (2-DG) or $30 \mathrm{mM}$ 5-thioglucose (5-TG). One $\mu$ M SIP was then added to the media for I5 seconds. Cells were then rapidly harvested and lysates prepared as described in the Methods section. 
More recently, S1P was shown also to potently enhance the in vitro motility of glioblastoma cells [39]. We thus assessed whether CHL could interfere with both basal and S1P-induced cell migration in U-87 cells, and if it could antagonize the G6PT-mediated regulation of cell migration. Control (Mock) or G6PT-transfected U-87 glioma cells were harvested and seeded on top of gelatin-coated filters as described in the Methods section. Cell migration then occurred in the presence of either $\mathrm{S} 1 \mathrm{P}, \mathrm{CHL}$, or a combination of both. Representative images of stained cells that had migrated through the filters are shown (Fig. $4 a)$. We observed that S1P induced basal cell migration by 2.6-fold, and that CHL was able to inhibit both the basal and S1P-induced cell migration (Fig. 4b, Mock). When cells were transiently transfected with the G6PT cDNA, basal cell migration increased by approximately 2 -fold, in accordance with Fig. 3b. Interestingly, the effect of S1P was additive to that of the overexpression of G6PT, but CHL efficiently antagonized migration that was induced either by G6PT overexpression or by S1P in G6PT-transfected cells (Fig. 4b, G6PT). These results suggest that G6PT potentially regulates the intracellular signalling that triggers basal and S1P-mediated cell migration, and that functional inhibition of this signalling by CHL could explain some of its chemopreventive effects at the molecular level.

\section{Chlorogenic acid inhibits sphingosine- I-phosphate- induced ERK phosphorylation in U-87 glioma cells}

$\mathrm{S} 1 \mathrm{P}$ is thought to trigger intracellular signalling, in part, through the MAPK pathway and the release of intracellular calcium pools $[38,40]$. We thus monitored the extent of ERK phosphorylation that is triggered by S1P in U-87 glioma cells and whether CHL could interfere with that process. S1P triggered a rapid phosphorylation of ERK within the first 15 seconds of incubation (Fig. 5, left panel). Interestingly, pre-incubation of the cells with 100 $\mu \mathrm{M}$ CHL for 30 minutes prevented that rapid phosphorylation of ERK and even delayed it until a time of $60 \mathrm{sec}-$ onds (Fig. 5, right panel). This inhibitory effect of CHL on S1P-induced ERK phosphorylation suggests that intracellular inhibition of microsomal G6PT activity may antagonize crucial events taking place in the ER.

\section{Intracellular ATP-depleting agents inhibit proMMP-2 secretion and antagonize SIP-induced ERK phosphorylation in U-87 glioma cells}

Besides its classical role in recognizing and translocating G6P from the cytoplasm into the lumen of the ER, G6PT has been attributed a possible role in regulating calcium flux responses $[41,42]$. Such a role in regulating intracellular calcium pools was elegantly demonstrated in neutrophils isolated from G6PT-deficient mice [43]. Interestingly, a functional link has been proposed between G6P and calcium such that cytoplasmic G6P is thought to enhance ATP-dependent sequestration of calcium in the ER [30]. In light of this, we sought to investigate the effects of the ATP-depleting agents and synthetic analogs of glucose, the glucose 5-thioglucose (5-TG) and the 2-deoxy-d-glucose (2-DG), on proMMP-2 secretion and S1P-induced ERK phosphorylation. U-87 glioma cells were serum-starved and treated with different concentrations of 2-DG and 5-TG. Conditioned media was isolated and the activity of secreted proMMP-2 was measured. ProMMP-2 secretion was significantly decreased in both 2-DG- and 5-TG-treated cells (Fig. 6a). Half-maximal inhibition constants $\left(\mathrm{IC}_{50}\right.$ ) were calculated to be $2 \mathrm{mM}$ and 19 $\mathrm{mM}$, respectively, for 2-DG and 5-TG (Fig. 6b). S1Pinduced ERK phosphorylation was also monitored in 2DG- and 5-TG pre-treated cells, and both ATP-depleting agents were able to inhibit S1P-induced ERK phosphorylation (Fig. 6c). Although these data are indirect, altogether they suggest that the inhibition of microsomal G6PT functions (inhibition of ER G6P uptake or of ATPdependent calcium sequestration) leads to decreased proMMP-2 secretion and a potential decrease in calciummediated intracellular signalization.

\section{Discussion}

As part of our continuing search for potential anticancer drug candidates, we pay great interest to natural products for their potential anticancer activities. As such, among the sources of anticancer polyphenols in tea constituents, CHL has recently caught our attention as it has been attributed chemopreventive properties [12-14]. Although CHL is known as the most potent inhibitor of G6PT, no study has yet demonstrated a role for G6PT in regulating tumor progression and metastasis. Our study now provides a molecular rationale to the anticancer properties of CHL in highly invasive brain tumor-derived U-87 glioblastoma cells. Indeed, we highlight a new and underestimated function for the microsomal G6PT as a potential regulator of cancer cells invasive phenotype. Besides its classical role in regulating the rate limiting step of G6P transport, G6PT specific functional inhibition by CHL even becomes more relevant when one considers G6PT's potential role in regulating calcium-mediated signalling. Such intracellular transduction events are known to regulate cancer cells proliferation, cell cycle division, ECM degradation, and response to growth factors. We now suggest that new cellular processes such as cell invasion, intracellular signal transduction in response to growth factors, and secretion of MMP may collectively be regulated in part through G6PT-mediated ER functions.

Interestingly, we extensively investigated and demonstrated that EGCg, another naturally occurring green teaderived polyphenol with anticancerous properties similar to those we describe for $\mathrm{CHL}$, can also efficiently target the brain tumor invasive phenotype by inhibiting RhoA/ 
Rock-mediated intracellular cell signalling [44]. Moreover, in light of recent studies which have shown that EGCg could also serve as an ionizing radiation (IR) enhancer against cancer cell lines [45], we have further shown that EGCg pretreatment of glioma cells prior to IR can reverse the cytoprotective effect provided through the expression of prosurvival proteins such as Survivin [46]. Functional inhibition of G6PT by either CHL or by the ATP-depleting agents 2-DG/5-TG could thus provide a molecular rationale for the role that G6PT may play in the intracellular signalling regulating the high-grade radioresistant glioma cells.

One important implication of our study is its potential impact on targeting G6PT functions in radiotherapeutic modalities. The failure of radiotherapy in cerebral gliomas is primarily due to the diffusely infiltrating nature of the tumor and the presence of a hypoxic, repair-proficient and intrinsically radioresistant subpopulation of cells. Since the chemopreventive properties of both the IR-cell sensitizing agent EGCg [46] and of CHL molecules [this study] are similarly and efficiently able to inhibit cell migration and MMP-secretion of glioblastoma cells, it is tempting to suggest that CHL may also be used in synergy with radiotherapeutic modalities. Enhanced glucose usage in vitro as well an in vivo, which correlates with the degree of malignancy and with poor prognosis, has been demonstrated in glioma tumors [52-54]. Moreover, in vitro studies in established glioma cell lines showed that the presence of 2-DG for a few hours after irradiation could increase radiation damage significantly and that radiosensitization was higher under conditions of reduced respiratory metabolism [55]. Finally, 2-DG is known to inhibit glycolytic energy ATP production [56] and has been tested in multiple studies for possible application as an anticancer or antiviral therapeutic [57-59]. Such observations provide another molecular rationale for the means by which $\mathrm{CHL}$, 2-DG and 5-TG that we report in the present study may inhibit G6PT functions, and that we have shown to be significantly expressed in U-87 glioblastoma cells.

Poorly differentiated and rapidly growing malignant tumors are generally characterized by higher rates of glucose usage and glycolysis as compared to corresponding normal tissues $[47,48]$. As such, these fundamental differences in the glucose metabolism of transformed and normal cells form the basis for the noninvasive detection and grading of tumors by positron emission tomography (PET) using tracer nanomolar doses of $\left[{ }^{18} \mathrm{~F}\right]$-2-fluorodeoxyglucose ([18F]FDG), a nonmetabolizable analog of glucose that enters the cell by the same membrane transport mechanism as does glucose. Measurements of glucose uptake into human tumors by FDG-PET suggest that glucose uptake may directly correlate with the degree of malignancy and treatment resistance/poor prognosis [49].
The precise molecular mechanisms underlying this correlation remain to be elucidated. Interestingly, the use of $\left[{ }^{18} \mathrm{~F}\right] \mathrm{FDG}$ was also employed in the monitoring of adenovirus-mediated GSD-1a correction [50], a disease characterized by a defect in the glucose-6-phosphatase catalytic subunit (G6Pase- $\alpha$ ). Therefore, similar to the non-metabolizable glucose analogue 2-DG, one can expect pharmacological doses of FDG to block glycolysis and to cause depletion of ATP. Interestingly, it has been shown that the killing of neoplastic cells by cytostatic drugs is associated with decreased ATP content and FDG uptake. This indicates that FDG uptake is closely linked with ATP production and that not only ATP but also FDG could be used to study drug effects in vitro [51].

We show that inhibiting G6PT functions by CHL or by ATP-depleting agents in brain-tumor-derived cells may result in decreased invasiveness. Moreover, because cancer cells frequently display high rates of aerobic glycolysis, in comparison to their nontransformed counterparts, the recently published hypoglycemic impact of CHL [60], combined with the possible applications of 2-DG in anticancer therapies, further supports the theory that inhibiting G6PT functions in cancer cells could decrease tumor progression. G6PT deficiencies lead to GSD type-Ib and chronic neutropenia because of impaired glucose homeostasis [41,42], altered neutrophil chemotaxis and calcium flux [43], and induction of cell apoptosis [22]. Concomitantly, CHL was recently found to inhibit human hepatocellular carcinoma cell line proliferation [14] and to induce apoptosis of chronic myelogenous leukemia (CML) cell lines and primary cells from CML patients [62]. Alternate cellular targets of CHL in glioma cells can not be excluded as its most extensively studied effects were attributed to its metal chelator, and that its anti-oxidative properties highlighted a role for ERK in oxidative stressinduced glioma cell death [63]. Although this remains to be investigated, it thus becomes tempting to hypothesis that the anti-oxidative properties of CHL may somehow prevent or protect from oxidative stress-induced cell death. Studies on the G6PT functions and contribution in neurodegenerative diseases may shed some clues as to its role and modulation by oxidative stress.

In summary, our study evidences that G6PT triggers cancer cell migration, and that CHL antagonized growth factors-induced calcium mobilization and ERK phosphorylation. The sum of these experimental evidences leads us to postulate a new role for G6PT in cancer cell signalling, and suggests that efficient inhibition of the G6PT functions will impact on the invasive and metastatic phenotype of circulating cancer cells whether they derive from solid tumors or from malignant clonal disorder of hematopoietic stem cells such as CML. 


\section{Methods \\ Materials}

Agarose, (-)-epigallocatechin 3-gallate (EGCg), sodium dodecylsulfate (SDS), gelatin, and bovine serum albumin (BSA) were purchased from Sigma (Oakville, ON). The TRIzol reagent was from Life Technologies (Gaithersburg, MD). FUGENE-6 transfection reagent was from Roche Diagnostics Canada (Laval, QC).

\section{Cell culture and cDNA transfection method}

The U-87, U-118 and U-138 glioma cell lines, the DAOY medulloblastoma cell line and the HEP-G2 hepatoma cell line were purchased from American Type Culture Collection and cultured in their recommended media. Specifically, U-87 cells were maintained in Eagle's Minimum essential medium (MEM) containing 10\% (v/v) fetal bovine serum (FBS) (HyClone Laboratories, Logan, UT), $2 \mathrm{mM}$ glutamine, $100 \mathrm{units} / \mathrm{ml}$ penicillin and $100 \mu \mathrm{g} / \mathrm{ml}$ streptomycin, and were cultured at $37^{\circ} \mathrm{C}$ under a humidified atmosphere containing 5\% $\mathrm{CO}_{2}$. The G6PT plasmid was validated and generously provided by Dr Christopher Newgard [35]. U-87 cells were transiently transfected with the cDNA construct using the non-liposomal formulation FUGENE-6 transfection reagent. Transfection efficiency was confirmed by RT-PCR. All experiments involving these cells were performed 36 hrs following transfection. Mock transfections of U-87 cultures with pcDNA (3.1+) expression vector alone were used as controls.

\section{Total RNA isolation and reverse transcriptase-polymerase chain reaction (RT-PCR) analysis}

Total RNA was extracted from cultured monolayers of U87 cells using the TRIzol reagent. One microgram of total RNA was used for first strand cDNA synthesis followed by specific gene product amplification with the One-Step RTPCR Kit (Invitrogen, Burlington, ON). Primers for G6Pase- $\alpha$ (forward : 5'-TTCAGCCACATCCACAGCATC3', reverse : 5'-GGGGTTTCAAGGAGTCAAAGACG-3'), for G6Pase- $\beta$ (forward : 5'-ACTCTTCCTGACTTCTTGTGTGCC-3', reverse : 5'-TTGCCTTTGCTCTTTGGGGG-3') and for G6PT (forward : 5'-CAGGGCTATGGCTATTATCGCAC-3', reverse : 5'-ATGGCTCAAACCACTTCCGCAG-3') were all derived from human sequences. Glyceraldehyde3-phosphate dehydrogenase (GAPDH) cDNA amplification was used as an internal house-keeping gene control. PCR conditions were optimized so that the gene products were examined at the exponential phase of their amplification and the products were resolved on $1.5 \%$ agarose gels containing $1 \mu \mathrm{g} / \mathrm{ml}$ ethidium bromide.

\section{Gelatin zymography}

Gelatin zymography was used to assess the extent of MMP-2 activity. Briefly, an aliquot $(20 \mu \mathrm{l})$ of the culture medium was subjected to SDS-PAGE in a gel containing $0.1 \mathrm{mg} / \mathrm{ml}$ gelatin. The gels were then incubated in $2.5 \%$
Triton X-100 and rinsed in nanopure distilled $\mathrm{H}_{2} \mathrm{O}$. Gels were further incubated at $37^{\circ} \mathrm{C}$ for $20 \mathrm{hrs}$ in $20 \mathrm{mM} \mathrm{NaCl}$, $5 \mathrm{mM} \mathrm{CaCl}_{2}, 0.02 \%$ Brij-35, $50 \mathrm{mM}$ Tris-HCl buffer, $\mathrm{pH}$ 7.6, then stained with $0.1 \%$ Coomassie Brilliant blue R250 and destained in 10\% acetic acid, 30\% methanol in $\mathrm{H}_{2} \mathrm{O}$. Gelatinolytic activity was detected as unstained bands on a blue background. The exogenous source of proMMP-2, used to assess MT1-MMP-mediated activation of proMMP-2 by concanavalin-A, was isolated from $48 \mathrm{hrs}$ serum starved-U87 glioma cells. This conditioned media contains high levels of latent proMMP-2 as well as TIMP2 necessary to for the ternary complex with MT1-MMP and to monitor any potential MT1-MMP-mediated activation of proMMP-2 activation.

\section{Immunoblotting procedures}

Proteins from control and treated cells were separated by SDS-polyacrylamide gel electrophoresis (PAGE). After electrophoresis, proteins were electrotransferred to polyvinylidene difluoride membranes which were then blocked overnight at $4{ }^{\circ} \mathrm{C}$ with $5 \%$ non-fat dry milk in Tris-buffered saline $(150 \mathrm{mM}$ Tris, $20 \mathrm{mM}$ Tris- $\mathrm{HCl}, \mathrm{pH}$ 7.5 ) containing $0.3 \%$ Tween-20 (TBST). Membranes were further washed in TBST and incubated with the primary antibodies (1/1,000 dilution) in TBST containing 3\% bovine serum albumin, followed by a $1 \mathrm{hr}$ incubation with horseradish peroxidase-conjugated anti-rabbit IgG (1/10,000 dilution) in TBST containing 5\% non-fat dry milk. Immunoreactive material was visualized by enhanced chemiluminescence (Amersham Biosciences, Baie d'Urfée, QC).

\section{Cell migration assay}

Cells were dislodged after brief trypsinization, washed extensively and resuspended in DMEM at a concentration of $10^{6}$ cells $/ \mathrm{ml}[35]$. Cells $\left(7 \times 10^{5}\right)$ were then dispersed onto $1 \mathrm{mg} / \mathrm{ml}$ gelatin/PBS-coated chemotaxis filters (Costar; $8-\mu \mathrm{m}$ pore size) within Boyden chamber inserts. Migration proceeded for $3 \mathrm{~h}$ at $37^{\circ} \mathrm{C}$ in $5 \% \mathrm{CO}_{2}$. Cells that had migrated to the lower surface of the filters were fixed with $10 \%$ formalin phosphate, colored with $0.1 \%$ crystal violet/20\% MeOH and counted by microscopic examination. The average number of migrating cells per field was assessed by counting at least four random fields per filter using Northern Eclipse software. Data points indicate the mean obtained from three separate chambers within one representative experiment.

\section{Statistical data analysis}

Data are representative of three or more independent experiments. Statistical significance was assessed using nonparametric one-way ANOVA with GraphPad Prism Version 4.0. Probability values of less than 0.05 were considered significant, and an asterisk $(*)$ identifies such significance in each figure. 


\section{Abbreviations}

ATP, adenosine triphosphate; $\mathrm{CHL}$, chlorogenic acid; 2DG, 2-deoxy-d-glucose; ECM, extracellular matrix; EGCg, epigallocatechin-(3)-gallate; ER, endoplasmic reticulum; ERK, extracellular signal-regulated protein kinases; G6P, glucose-6-phosphate; G6Pase, glucose-6-phosphatase; G6PT, G6P translocase; GSD, glycogen storage disease; IR, ionizing radiation; MMP, matrix metalloproteinase; 5-TG, 5-thioglucose.

\section{Acknowledgements}

B.A. holds a Canada Research Chair in Molecular Oncology (Tier-II) from the Canadian Institutes of Health Research.

\section{References}

I. Manach C, Scalbert A, Morand C, Remesy C, Jimenez L: Polyphenols: food sources and bioavailability. Am J Clin Nutr 2004, 79:727-747.

2. Stoclet JC, Chataigneau T, Ndiaye M, Oak MH, El Bedoui J, Chataigneau M, Schini-Kerth VB: Vascular protection by dietary polyphenols. Eur J Pharmacol 2004, 500:299-3I3.

3. Scalbert A, Manach C, Morand C, Remesy C, Jimenez L: Dietary polyphenols and the prevention of diseases. Crit Rev Food Sci Nutr 2005, 45:287-306.

4. Arts IC, Hollman PC: Polyphenols and disease risk in epidemiologic studies. Am J Clin Nutr 2005, 81:317S-325S.

5. Block G, Patterson B, Subar A: Fruit, vegetables and cancer prevention: a review of the epidemiological evidence. Nutr Cancer 1992, I 8: I-30.

6. Lambert JD, Hong J, Yang GY, Liao J, Yang CS: Inhibition of carcinogenesis by polyphenols: evidence from laboratory investigations. Am J Clin Nutr 2005, 81:284S-29IS.

7. Kanadaswami C, Lee LT, Lee PP, Hwang J, Ke FC, Huang YT, Lee MT: The antitumor activities of flavonoids. In Vivo 2005, 1 9:895-909.

8. Roudebush P, Davenport DJ, Novotny BJ: The use of nutraceuticals in cancer therapy. Vet Clin North Am Small Anim Pract 2004 34:249-269.

9. Zhu X, Chen B, Ma M, Luo X, Zhang F, Yao S, Wan Z, Yang D, Hang $\mathrm{H}$ : Simultaneous analysis of theanine, chlorogenic acid, purine alkaloids and catechins in tea samples with the help of multi-dimension information of on-line high performance liquid chromatography/electrospray-mass spectrometry. J Pharm Biomed Anal 2004, 34:695-704.

10. Moyers SB, Kumar NB: Green tea polyphenols and cancer chemoprevention: multiple mechanisms and endpoints for phase II trials. Nutr Rev 2004, 62:204- I I.

II. Kazi A, Smith DM, Daniel K, Zhong S, Gupta P, Bosley ME, Dou QP: Potential molecular targets of tea polyphenols in human tumor cells: significance in cancer prevention. In Vivo 2002, 1 6:397-403.

12. Mori H, Kawabata K, Matsunaga K, Ushida J, Fujii K, Hara A, Tanaka $T$, Murai $H$ : Chemopreventive effects of coffee bean and rice constituents on colorectal carcinogenesis. Biofactors 2000, I 2:101-105.

13. Chiang YM, Chuang DY, Wang SY, Kuo YH, Tsai PW, Shyur LF: Metabolite profiling and chemopreventive bioactivity of plant extracts from Bidens pilosa. J Ethnopharmacol 2004, 95:409-419.

14. Jin UH, Lee JY, Kang SK, Kim JK, Park WH, Kim JG, Moon SK, Kim $\mathrm{CH}$ : A phenolic compound, 5-caffeoylquinic acid (chlorogenic acid), is a new type and strong matrix metalloproteinase-9 inhibitor: isolation and identification from methanol extract of Euonymus alatus. Life Sci 2005, 77:2760-2769.

15. Yen WJ, Wang BS, Chang LW, Duh PD: Antioxidant properties of roasted coffee residues. I Agric Food Chem 2005, 53:2658-2663.

16. Krakauer T: The polyphenol chlorogenic acid inhibits staphylococcal exotoxin-induced inflammatory cytokines and chemokines. Immunopharmacol Immunotoxicol 2002, 24: I I3-I I9.

17. Herling AW, Burger HJ, Schwab D, Hemmerle H, Below P, Schubert G: Pharmacodynamic profile of a novel inhibitor of the hepatic glucose-6-phosphatase system. Am J Physiol 1998, 274:GI087-GI093.

18. van Dijk TH, van der Sluijs FH, Wiegman CH, Baller JF, Gustafson LA, Burger HJ, Herling AW, Kuipers F, Meijer AJ, Reijngoud DJ: Acute inhibition of hepatic glucose-6-phosphatase does not affect gluconeogenesis but directs gluconeogenic flux toward glycogen in fasted rats. A pharmacological study with the chlorogenic acid derivative S4048. J Biol Chem 200I, 276:25727-25735.

19. Bandsma RH, Wiegman $\mathrm{CH}$, Herling AW, Burger HJ, ter Harmsel A, Meijer AJ, Romijn JA, Reijngoud DJ, Kuipers F: Acute inhibition of glucose-6-phosphate translocator activity leads to increased de novo lipogenesis and development of hepatic steatosis without affecting VLDL production in rats. Diabetes 2001 , 50:2591-2597.

20. Hemmerle H, Burger HJ, Below P, Schubert G, Rippel R, Schindler PW, Paulus E, Herling AW: Chlorogenic acid and synthetic chlorogenic acid derivatives: novel inhibitors of hepatic glucose6-phosphate translocase. J Med Chem 1997, 40: I37-I45.

2I. Arion WJ, Canfield WK, Ramos FC, Schindler PW, Burger HJ, Hemmerle H, Schubert G, Below P, Herling AW: Chlorogenic acid and hydroxynitrobenzaldehyde: new inhibitors of hepatic glucose 6-phosphatase. Arch Biochem Biophys 1997, 339:3 I5-322.

22. Leuzzi R, Banhegyi G, Kardon T, Marcolongo P, Capecchi PL, Burger HJ, Benedetti A, Fulceri R: Inhibition of microsomal glucose-6phosphate transport in human neutrophils results in apoptosis: a potential explanation for neutrophil dysfunction in glycogen storage disease type Ib. Blood 2003, I 0 I:238I-2387.

23. Hiraiwa H, Pan CJ, Lin B, Moses SW, Chou JY: Inactivation of the glucose 6-phosphate transporter causes glycogen storage disease type Ib. J Biol Chem 1999, 274:5532-5536.

24. Calderwood S, Kilpatrick L, Douglas SD, Freedman M, Smith-Whitley $\mathrm{K}$, Rolland M, Kurtzberg J: Recombinant human granulocyte colony-stimulating factor therapy for patients with neutropenia and/or neutrophil dysfunction secondary to glycogen storage disease type Ib. Blood 2001, 97:376-382.

25. Beaudet AL, Anderson DC, Michels VV, Arion WJ, Lange AJ: Neutropenia and impaired neutrophil migration in type IB glycogen storage disease. J Pediatr 1980, 97:906-910.

26. Kilpatrick L, Garty BZ, Lundquist KF, Hunter K, Stanley CA, Baker L, Douglas SD, Korchak HM: Impaired metabolic function and signalling defects in phagocytic cells in glycogen storage disease type Ib. J Clin Invest 1990, 86:196-202.

27. Bashan N, Potashnik R, Peist A, Peleg N, Moran A, Moses SW: Deficient glucose phosphorylation as a possible common denominator and its relation to abnormal leucocyte function, in glycogen storage disease Ib patients. Eur J Pediatr 1993, 152:S44-S48.

28. Korchak HM, Garty BZ, Stanley CA, Baker L, Douglas SD, Kilpatrick $\mathrm{L}$ : Impairment of calcium mobilization in phagocytic cells in glycogen storage disease type Ib. Eur J Pediatr 1993, I52:S39-S43.

29. Potashnik R, Moran A, Moses SW, Peleg N, Bashan N: Hexose uptake and transport in polymorphonuclear leukocytes from patients with glycogen storage disease Ib. Pediatr Res 1990, 28:19-23

30. Chen PY, Csutora P, Veyna-Burke NA, Marchase RB: Glucose-6phosphate and $\mathrm{Ca2}+$ sequestration are mutually enhanced in microsomes from liver, brain, and heart. Diabetes 1998 , 47:874-88I

31. Arion WJ, Canfield WK, Ramos FC, Su ML, Burger HJ, Hemmerle H, Schubert G, Below P, Herling AW: Chlorogenic acid analogue S3483: a potent competitive inhibitor of the hepatic and renal glucose-6-phosphatase systems. Arch Biochem Biophys 1998, 35 1:279-285.

32. Ghosh A, Cheung YY, Mansfield BC, Chou JY: Brain contains a functional glucose-6-phosphatase complex capable of endogenous glucose production. J Biol Chem 2005, 280: I I I I4- I I I I9.

33. Konishi Y, Kobayashi S: Transepithelial transport of chlorogenic acid, caffeic acid, and their colonic metabolites in intestinal caco-2 cell monolayers. J Agric Food Chem 2004, 52:25 I8-2526.

34. Annabi B, Lachambre MP, Bousquet-Gagnon N, Page M, Gingras D, Beliveau R: Green tea polyphenol (-)-epigallocatechin 3-gallate inhibits MMP-2 secretion and MTI-MMP-driven migration in glioblastoma cells. Biochim Biophys Acta 2002, I 542:209-220. 
35. Annabi B, Lachambre MP, Bousquet-Gagnon N, Page M, Gingras D, Beliveau R: Localization of membrane-type I matrix metalloproteinase in caveolae membrane domains. Biochem J 200I, 353:547-553.

36. An J, Li Y, van De Werve G, Newgard CB: Overexpression of the P46 (TI) translocase component of the glucose-6-phosphatase complex in hepatocytes impairs glycogen accumulation via hydrolysis of glucose I-phosphate. J Biol Chem 200I, 276: 10722-10729.

37. Edsall LC, Spiegel S: Enzymatic measurement of sphingosine-Iphosphate. Anal Biochem 1999, 272:80-86.

38. Van Brocklyn JR, Letterle CA, Snyder PJ, Prior TW: Sphingosine-Iphosphate stimulates human glioma cell proliferation through $G_{i}$-coupled receptors: Role of ERK MAP kinase and phosphatidylinositol 3-kinase $\beta$. Cancer Lett 2002, I 8 I: 195-204.

39. Van Brocklyn JR, Young N, Roof R: Sphingosine-I-phosphate stimulates motility and invasiveness of human glioblastoma multiforme cells. Cancer Lett 2003, 199:53-60.

40. Young KW, Nahorski SR: Sphingosine I-phosphate: a Ca2+ release mediator in the balance. Cell Calcium. Cell Calcium 2002, 32:335-341.

41. Gitzelmann R, Bosshard NU: Defective neutrophil and monocyte functions in glycogen storage disease type lb: a literature review. Eur J Pediatr 1993, 152:S33-S38.

42. Garty BZ, Douglas SD, Danon YL: Immune deficiency in glycogen storage disease type IB. Isr J Med Sci 1996, 32:I276-128I.

43. Chen LY, Shieh JJ, Lin B, Pan CJ, Gao JL, Murphy PM, Roe TF, Moses S, Ward JM, Lee E), Westphal H, Mansfield BC, Chou JY: Impaired glucose homeostasis, neutrophil trafficking and function in mice lacking the glucose-6-phosphate transporter. Hum Mol Genet 2003, 1 2:2547-2558.

44. Annabi B, Bouzeghrane M, Moumdjian R, Moghrabi A, Beliveau R: Probing the infiltrating character of brain tumors: inhibition of RhoA/ROK-mediated CD44 cell surface shedding from glioma cells by the green tea catechin EGCg. J Neurochem 2005, 94:906-916.

45. Baatout S, Jacquet P, Derradji H, Ooms D, Michaux A, Mergeay M: Study of the combined effect of $X$-irradiation and epigallocatechin-gallate (a tea component) on the growth inhibition and induction of apoptosis in human cancer cell lines. Oncol Rep 2004, 12:159-167.

46. McLaughlin N, Annabi B, Bouzeghrane M, Temme A, Bahary JP, Moumdjian R, Béliveau R: The Survivin-mediated radioresistant phenotype of glioblastomas is regulated by RhoA and inhibited by the green tea polyphenol (-)-epigallocatechin-3-gallate. Brain Research 2006, I07I:I-9.

47. Warburg O, Posener K, Negelein E: The metabolism of cancer cells. Biochem Zeitschr 1934, I 52:129-169.

48. Mathupala SP, Rempel A, Pedersen PL: Glucose catabolism in cancer cells: identification and characterization of a marked activation response of the type II hexokinase gene to hypoxic conditions. J Biol Chem 200I, 276:43407-434I2.

49. Kostakoglu L, Hardoff R, Mirtcheva R, Goldsmith SJ: PET-CT fusion imaging in differentiating physiologic from pathologic FDG uptake. Radiographics 2004, 24: I4II-I43I.

50. Zingone A, Seidel J, Aloj L, Caraco C, Vaquero J], Jagoda EM, Chou JY, Green MV, Eckelman WC: Monitoring the correction of glycogen storage disease type $\mathrm{la}$ in a mouse model using [(I8)F]FDG and a dedicated animal scanner. Life Sci 2002, 71:1293-1301.

51. Minn H, Kangas L, Knuutila V, Paul R, Sipila H: Determination of 2fluoro-2-deoxy-D-glucose uptake and ATP level for evaluating drug effects in neoplastic cells. Res Exp Med (Berl) I99I, | $91: 27-35$.

52. Timperley WR: Glycolysis in neuroectodermal tumours. In: Thomas DGT, Graham DI, eds. Brain tumours. Scientific basis, clinical investigation and current therapy. London: Butterworth's; 1980:145-167.

53. Di Chiro G, Brooks RA, Patronas NJ, Bairamian D, Kornblith PL, Smith BH, Mansi L, Barker J: Issues in the in vivo measurement of glucose metabolism of human central nervous system tumors. Ann Neurol 1984, 15:SI38-SI 46.

54. Padma MV, Said S, Jacobs M, Hwang DR, Dunigan K, Satter M, Christian B, Ruppert J, Bernstein T, Kraus G, Mantil JC: Prediction of pathology and survival by FDG PET in gliomas. J Neurooncol 2003, 64:227-237.
55. Dwarakanath BS, Jain VK: Modification of the radiation induced damage by 2-deoxy-D-glucose in organ cultures of human cerebral gliomas. Int J Radiat Oncol Biol Phys 1987, I3:74I-746.

56. Woodward GE, Hudson MT: The effect of 2-desoxy-D-glucose on glycolysis and respiration of tumor and normal tissues. Cancer Res 1954, 14:599-605.

57. Singh D, Banerji AK, Dwarakanath BS, Tripathi RP, Gupta JP, Mathew $T L$, Ravindranath T, Jain V: Optimizing cancer radiotherapy with 2-deoxy-d-glucose dose escalation studies in patients with glioblastoma multiforme. Strahlenther Onkol 2005, I 8 I:507-5 I4.

58. Kang HT, Hwang ES: 2-Deoxyglucose: An anticancer and antiviral therapeutic, but not any more a low glucose mimetic. Life Sci 2006, 78: 1392-1399.

59. Xu RH, Pelicano H, Zhou Y, Carew JS, Feng L, Bhalla KN, Keating MJ, Huang P: Inhibition of glycolysis in cancer cells: a novel strategy to overcome drug resistance associated with mitochondrial respiratory defect and hypoxia. Cancer Res 2005, 65:6|3-62|.

60. Nicasio P, Aguilar-Santamaria L, Aranda E, Ortiz S, Gonzalez M: Hypoglycemic effect and chlorogenic acid content in two Cecropia species. Phytother Res 2005, 19:66I-664.

61. Hahn-Windgassen A, Nogueira V, Chen CC, Skeen JE, Sonenberg N, Hay N: Akt activates the mammalian target of rapamycin by regulating cellular ATP level and AMPK activity. J Biol Chem 2005, 280:3208I-32089.

62. Bandyopadhyay G, Biswas T, Roy KC, Mandal S, Mandal C, Pal BC, Bhattacharya S, Rakshit S, Bhattacharya DK, Chaudhuri U, Konar A, Bandyopadhyay S: Chlorogenic acid inhibits Bcr-Abl tyrosine kinase and triggers p38 mitogen-activated protein kinasedependent apoptosis in chronic myelogenous leukemic cells. Blood 2004, 104:25।4-2522.

63. Lee WC, Choi CH, Cha SH, Oh HL, Kim YK: Role of ERK in hydrogen peroxide-induced cell death of human glioma cells. Neurochem Res 2005, 30:263-270.
Publish with Biomed Central and every scientist can read your work free of charge

"BioMed Central will be the most significant development for disseminating the results of biomedical research in our lifetime. "

Sir Paul Nurse, Cancer Research UK

Your research papers will be:

- available free of charge to the entire biomedical community

- peer reviewed and published immediately upon acceptance

- cited in PubMed and archived on PubMed Central

- yours - you keep the copyright

Submit your manuscript here:

http://www.biomedcentral.com/info/publishing_adv.asp
BioMedcentral 